Acta Crystallographica Section D

Biological Crystallography

ISSN 0907-4449

Marie Hedrén, ${ }^{a}$ Andras Ballagi, ${ }^{\text {b }}$ Lars Mörtsell, ${ }^{\text {b }}$ Gyogy Rajkai, ${ }^{\text {b }}$ Pål Stenmark, ${ }^{\mathrm{a}}$ Christer Sturesson $^{\mathrm{b}}$ and Pär Nordlund ${ }^{\mathrm{a} *}$

a Department of Medical Biochemistry and Biophysics, Karolinska Institutet,

SE-109 51 Stockholm, Sweden, and ${ }^{\mathbf{b}}$ Belach Bioteknik AB, Ingentingsgatan 2, Solna, Sweden

Correspondence e-mail: par.nordlund@ki.se

\title{
GRETA, a new multifermenter system for structural genomics and process optimization
}

As part of the Structural Proteomics In Europe (SPINE) project, the automated multifermenter system GRETA has been developed with structural genomics as a major application. GRETA comprises 6-24 parallel fermentation chambers, each with individual control of fermentation parameters such as temperature, stirring, $\mathrm{pH}$, dissolved oxygen concentration and feed profiles. Six human proteins were used to optimize the GRETA fermentation processes and to compare these processes with typical baffled-flask protocols used in structural genomics projects. The optimized GRETA processes allows several times more protein to be produced per litre of culture with limited manual intervention and constitutes a potentially useful alternative both for scale-up production in structural proteomic projects and for fermentation-process optimization.

\section{Background}

Structural genomics programmes aim at establishing costefficient pipelines for the production of large numbers of different proteins. The pioneering protein-production efforts in structural genomics were focused on implementing streamlined and robust protocols for the production of prokaryotic proteins and evaluating their efficiency (Edwards et al., 2000; Heinemann et al., 2000; Dieckman et al., 2002). At present, protein production in structural genomics still employs relatively simple expression and purification strategies.

Streamlined protein-production strategies based on an Escherichia coli expression system followed by scale-up fermentation in baffled shake flasks and one or two generic purification steps have been the common denominator for successful projects targeting prokaryotic proteins. However, the cost of producing proteins in the quantities required for structural studies is still relatively high, partially owing to the extensive manual interventions required for the scale-up process. Progress on eukaryotic proteins has been lagging behind because they are more difficult to produce than prokaryotic proteins in suitable quantity and quality for structural studies. Generic protein-production methods for eukaryotic proteins are still likely to require more complex technologies and strategies than those used for prokaryotic proteins. The efficient scale-up production of poorly expressing proteins and protein domains will most probably be an important component of these strategies. In addition, the scale-up production of several different constructs of each eukaryotic protein or protein domain is likely to be a key component. Therefore, the automation and integration of the scale-up process will be essential in future structural genomics projects both to allow cost reduction and for the efficient
Received 7 December 2005 Accepted 27 August 2006
(C) 2006 International Union of Crystallography Printed in Denmark - all rights reserved 
production of proteins expressing at only low or medium levels (Lesley \& Wilson, 2005).

Culture in baffled flasks is currently the main solution for scale-up fermentation in structural genomics programmes. Using rich media, cell densities in the region of 10-25 OD can be routinely obtained from streamlined fermentation protocols. However, the maintenance of these cultures is timeconsuming since it includes preparation and harvesting as well as the monitoring of the OD. Recently, media allowing autoinduction have been developed so that OD measurements are not required to determine the induction time (Studier, 2005). However, protein expression in these media often takes place in the stationary phase, which could potentially lead to the

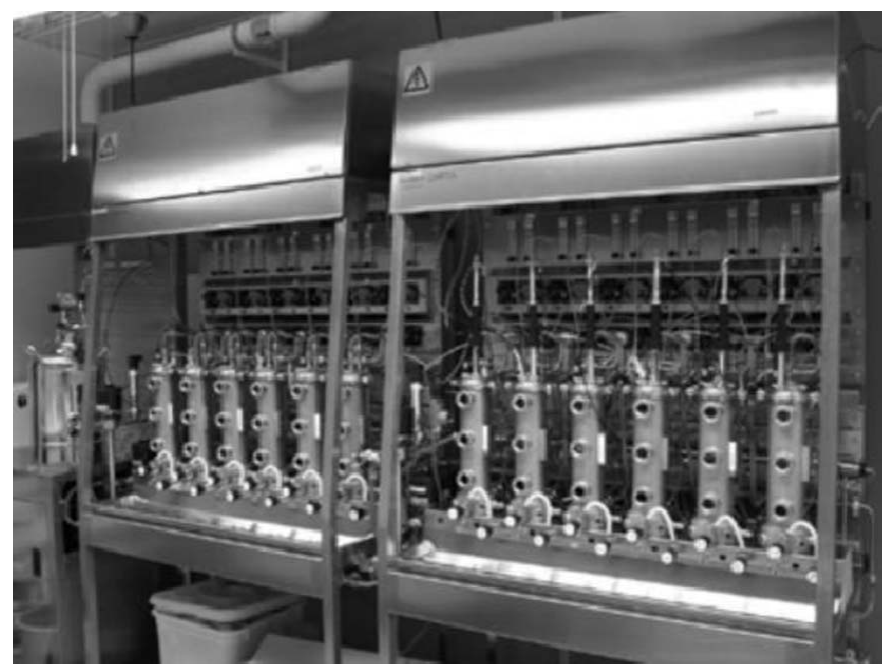

Figure 1

The bioprocess unit of GRETA, encompassing 12 fermentation chambers. production of lower levels of soluble proteins. In cases when re-growth is required to produce additional batches of protein, the reproducibility of baffled-flask cultures is also a potential problem, as they have a low level of control and are potentially more exposed to infections than closed fermenter systems.

As an alternative to baffled-flask cultures, parallel bubbleflask fermentation devices have also been developed for structural genomics applications (Lesley \& Wilson, 2005). The bubble flasks allow larger numbers of fermentations to be performed in a limited space and slightly higher cell densities can be produced in each unit of culture than in baffled shake flasks. Novartis Institute are routinely using 96 bubbled flasks, each allowing $80 \mathrm{ml}$ cultures (Lesley \& Wilson, 2005). However, bubble-flask fermentation systems still require a similar level of manual intervention as shake-flask culturing and are not yet used by the broader structural genomics community.

Highly automated fermenters equipped with more extensive fermentation-control systems provide the potential for producing high-density cell cultures as well as a high degree of reproducibility. They also provide an automated platform onto which harvesting and further cell processing can potentially be added. So far, however, fermenters have not yet been extensively used in structural genomics projects, although a number of programmes have investigated their usefulness. One major reason for the lack of use of fermenters in structural genomics is that appropriate commercial fermenters have been lacking on the market.

In the present study, we have developed a multi-fermentation system, GRETA, specifically designed for the needs of structural genomics programme. We used GRETA to establish a high cell density for producing six human proteins. We showed that this process allowed high cell densities to be produced without losing the amount of soluble protein per cell compared with the values reached in typical baffled-flask cultures. Therefore, GRETA provides a potential platform for the efficient scale-up of fermentations in structural genomics programmes.

\section{The GRETA multifermenter}

The GRETA multifermenter system consists of bioreactor units, each encompassing six parallel fermentation chambers (Fig. 1). Up to four bioreactor units (24 parallel fermenter chambers) can be integrated into one GRETA system. Each fermenter chamber is built using stainless steel with either 0.5 or 11 maximum working volume. The 11 fermenter chamber allows fermentations in the range $0.2-11$. Each chamber is equipped with a magnetic coupled
Figure 2

The GRETA BioPhantom software displaying the configuration and output parameters for one of four possible bioprocessor units A-D. 
Table 1

Compositions of media.

TB, Terrific broth. SMM, Supported minimal media.

\begin{tabular}{|c|c|c|c|}
\hline $\begin{array}{l}\text { Base medium } \\
\left(\begin{array}{ll}1 & 1\end{array}\right)\end{array}$ & $\begin{array}{l}\text { TB, } \\
\text { shake flask }\end{array}$ & $\begin{array}{l}\text { SMM, } \\
\text { shake flask }\end{array}$ & $\begin{array}{l}\text { SMM, } \\
\text { fermenter }\end{array}$ \\
\hline Tryptone (g) & 12 & 10 & 10 \\
\hline $\mathrm{CaCl}_{2}(\mathrm{mg})$ & & & 14.7 \\
\hline Yeast extract (g) & 24 & 5 & 5 \\
\hline Glycerol (g) & 40 & 5 & 5 \\
\hline $\mathrm{K}_{2} \mathrm{HPO}_{4}(\mathrm{~g})$ & 2.31 & 5 & 5 \\
\hline $\mathrm{KH}_{2} \mathrm{PO}_{4}(\mathrm{~g})$ & 12.5 & 4 & 4 \\
\hline Sodium citrate (g) & & & 0.5 \\
\hline$\left(\mathrm{NH}_{4}\right)_{2} \mathrm{SO}_{4}(\mathrm{~g})$ & & 2.5 & 2.5 \\
\hline $\mathrm{MgSO}_{4} \cdot 7 \mathrm{H}_{2} \mathrm{O}(\mathrm{g})$ & 0.98 & 0.98 & 0.98 \\
\hline Thiamine- $\mathrm{HCl}(\mathrm{mg})$ & 2 & 2 & 7 \\
\hline Vitamin mix (ml) & & & 1 \\
\hline Trace elements (ml) & 1 & 1 & 1 \\
\hline
\end{tabular}

bottom stirrer with combined impeller/sparger, sterile air filter and an $\mathrm{O}_{2} / \mathrm{N}_{2} /$ air gas-mixing system. A single cleaning-in-place (CIP) station supports the 1-4 bioreactor units of a GRETA system. This unit provides the high-pressure washing fluids for CIP, vessels and transfer lines, as well as for media preparation and for temperature regulation. All parts in contact with media or product can be sterilized-in-place (SIP) before filling media into the six fermenters. Optional sterilization can also be executed with the media inside the fermenters. The GRETA multifermenter system is controlled by the GRETA BioPhantom program, which allows for full control of all fermenter chambers, from sterilization to harvest (Fig. 2). Each chamber is individually controlled and potentially allows for the regulation of dissolved oxygen concentration (DO), $\mathrm{pH}$, temperature and stirring. Feeding profiles for media addition as well as induction can also be individually applied in each fermenter. Calibration of sensors is performed in parallel and in a semi-automated mode to minimize set-up time. The GRETA BioPhantom program has been specifically designed to facilitate the setup of parallel fermentation runs and to monitor data from parallel fermentation runs (Fig. 3). The system also provides acquisition of process and operational data to a data historian for reporting and archiving.

The GRETA fermenter can be equipped differently depending on the intended application. For structural geno-

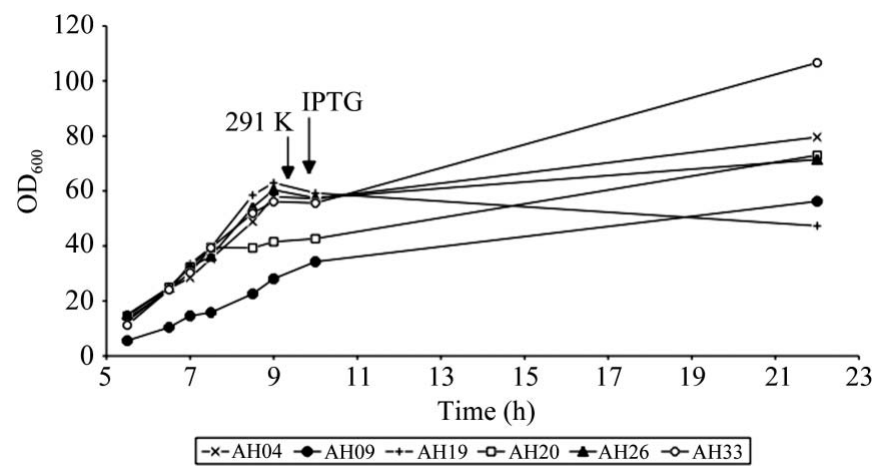

Figure 3

Growth curves of six different proteins expressed in BL21(DE3), growing in Supported minimal media with Terrific broth feed. mics applications, where streamlined processes will be executed, it is anticipated that a lower level of control might be needed than for a system used in, for example, process optimization of biopharmaceuticals. The GRETA system used in the present study was configured with two bioprocess units (12 fermentation chambers). Each chamber was equipped with four pumps (primarily for $\mathrm{pH}$ control and fed-batch), $\mathrm{pH}$ sensor and dissolved oxygen sensor, but was without gassensors. The system is also equipped with pneumatic syringes for automatic induction. Optical density is measured in each reactor by a built-in photometer. After calibration, this device allows accurate OD measurement within specified absorption intervals, set to 10-50 OD in the system used in the present study.

\section{Materials and methods}

\subsection{Bacterial strain and plasmid}

E. coli strain BL21(DE3) was transformed with six different human phosphatase-associated genes. The genes AH04 (PPME1_HUMAN), AH09 (PP2CG_HUMAN), AH19 (IPP1_HUMAN), AH20 (IPPD_HUMAN), AH26 (PP1R8_HUMAN) and AH33 (PP2BA_HUMAN) were cloned into Gateway-adapted vector pT7\#3.3 (AstraZeneca) with an N-terminal FLAG tag and a C-terminal His purification tag $\left(\mathrm{His}_{6}\right)$.

\subsection{Media preparations}

The compositions of the culture solutions used in the experiment are listed in Table 1 . The feeding medium (TB feed) contained (per litre of distilled water): tryptone (46.5 g), yeast extract $(46.5 \mathrm{~g})$, glycerol $(600 \mathrm{~g}), \mathrm{MgSO}_{4} \cdot 7 \mathrm{H}_{2} \mathrm{O}(3 \mathrm{~g})$ and trace elements $(1 \mathrm{ml})$. Tetracycline was added to a final concentration of $30 \mu \mathrm{g} \mathrm{ml}^{-1}$ for selection. Stock solutions of magnesium sulfate, glycerol, polypropylene glycol (PPG 2000) and trace elements were separately sterilized for $20 \mathrm{~min}$ at $394 \mathrm{~K}$. The trace-element solution contained (per litre of distilled water): $\mathrm{FeCl}_{3} \cdot 6 \mathrm{H}_{2} \mathrm{O}(54 \mathrm{~g}), \mathrm{ZnSO}_{4} \cdot 7 \mathrm{H}_{2} \mathrm{O}(22 \mathrm{~g})$, $\mathrm{CoCl}_{2} \cdot 6 \mathrm{H}_{2} \mathrm{O}(0.5 \mathrm{~g}), \mathrm{Na}_{2} \mathrm{MoO}_{4} \cdot 2 \mathrm{H}_{2} \mathrm{O}(0.5 \mathrm{~g}), \mathrm{CuSO}_{4} \cdot 5 \mathrm{H}_{2} \mathrm{O}$ $(0.13 \mathrm{~g}), \mathrm{H}_{3} \mathrm{BO}_{3}(0.5 \mathrm{~g}), \mathrm{MnSO}_{4} \cdot \mathrm{H}_{2} \mathrm{O}(11 \mathrm{~g})$ and concentrated $\mathrm{H}_{2} \mathrm{SO}_{4}(10 \mathrm{ml})$. Thiamine stock $\left(2 \mathrm{mg} \mathrm{ml}^{-1}\right)$ and IPTG (isopropyl $\beta$-D-galactopyranoside) stock $\left(476 \mathrm{mg} \mathrm{l}^{-1}\right)$ were sterilized by filtration and stored at $253 \mathrm{~K}$. Antifoam PPG 2000 was added at the beginning and, if needed, at induction.

A working cell bank (WCB) was prepared for each of the constructs and used to make seed cultures for all the fermentations. A colony was collected and grown overnight in LB medium and used to inoculate $50 \mathrm{ml} \mathrm{LB}$ with $0.1 \%$ glycerol in a $250 \mathrm{ml}$ Erlenmeyer flask. The WCBs were grown

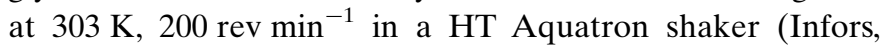
Switzerland) until $\mathrm{OD}_{600}$ was between 0.1 and 0.3 . Glycerol was added to a final concentration of $17 \%$ and the suspension was stored at $193 \mathrm{~K}$ in $1 \mathrm{ml}$ aliquots. Inoculum cultures were made before each experiment by adding $50 \mu \mathrm{lWCB}$ to $50 \mathrm{ml}$ LB with $1 \%$ glycerol and were allowed to grow at $303 \mathrm{~K}$ for 12-14 h. 


\subsection{Expression in baffled flask}

Cultures of $800 \mathrm{ml}$ medium (Table 1) in a 21 baffled flask were inoculated with $20 \mathrm{ml}$ inoculum and incubated at $310 \mathrm{~K}$ and $200 \mathrm{rev} \mathrm{min}^{-1}$. At an $\mathrm{OD}_{600}$ of $\sim 5$, the temperature was reduced to $291 \mathrm{~K}$ over $40 \mathrm{~min}$ followed by IPTG induction ( $0.5 \mathrm{~m} M$ final concentration). Cultures continued to grow at $291 \mathrm{~K}$ overnight and were harvested by centrifugation.

\subsection{Expression in fermenters}

Fermenter experiments were carried out in the GRETA multifermenter system (Belach Bioteknik AB, Sweden) with a fermentation volume of 11 in each reactor. E. coli BL21(DE3) were grown at $310 \mathrm{~K}$ with stirring initially set at $500 \mathrm{rev} \mathrm{min}^{-1}$ and the OD was measured every $15 \mathrm{~min}$. The $\mathrm{pH}$ was adjusted to between 6.8 and 7.1 by adding $14 \%(v / v)$ ammonia solution or $28 \%(v / v)$ phosphoric acid. The dissolved oxygen concentration (DO) in the bioreactor was controlled to maintain constant levels of $>30 \%$ air saturation by varying the stirrer speed up to $1500 \mathrm{rev} \mathrm{min}^{-1}$. Inoculation, antifoam, IPTG and acid, base or feed were transferred into the reactors through a fill port with a septum in the lid. Sample removal took place through a septum port in the lower side wall. Both the batch and fed-batch cultures start with $800 \mathrm{ml}$ medium (Table 1) in the reactor and the $\mathrm{pH}$ was adjusted to between 6.8 and 7.0. Antifoam $(1 \mathrm{ml})$ and $20 \mathrm{ml}$ inoculum were added to the reactors to initiate growth. Fed-batch mode was initiated by adding feed solution at an exponential feed rate to ensure 0.3$0.41 \mathrm{~h}^{-1}$ specific growth rate until the $\mathrm{OD}_{600}$ reached 50 . The fermentation temperature was reduced to $291 \mathrm{~K}$ and the glycerol feed rate was reduced to ensure $0.11 \mathrm{~h}^{-1}$ specific growth rate. Protein expression was started with the addition of $400 \mathrm{~m} M$ IPTG. Cells were grown for 14-15 h until harvest.

\subsection{Harvest}

The $\mathrm{OD}_{600}$ was determined in samples diluted 1/100. Shaker and fermenter cultures corresponding to $160 \mathrm{OD}_{600}$ units were centrifuged at $4500 \mathrm{rev} \mathrm{m^{-1 }}$ for $15 \mathrm{~min}$ at $277 \mathrm{~K}$ and the pellets were stored at $193 \mathrm{~K}$ pending analysis.

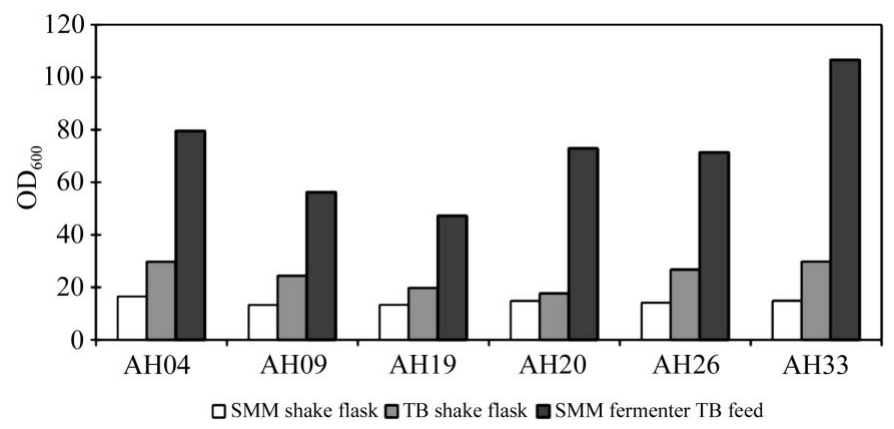

Figure 4

Comparison of $\mathrm{OD}_{600}$ when harvest from shaker-flask cultures and GRETA multi-fermentations. TB, Terrific broth. SMM, Supported minimal media.

\subsection{Ni-purification and dot-blot}

The frozen pellet was resuspended in $2 \mathrm{ml}$ cell lysis buffer [20 m $M$ Tris- $\mathrm{HCl} \mathrm{pH} 8.0,300 \mathrm{~m} M \mathrm{NaCl}, 1 \mathrm{mg} \mathrm{ml}^{-1}$ lysozyme, $10 \mathrm{U} \mathrm{ml}^{-1}$ benzonase, $0.1 \% n$-dodecyl $\beta$-maltoside (DDM), $5 \%$ glycerol, $1 \mathrm{mM} \mathrm{MgSO}_{4}, 1 \times$ Complete protease-inhibitor EDTA-free tablet per $25 \mathrm{ml}, 5 \mathrm{~m} M \beta$-mercaptoethanol] under non-denaturing conditions. Cells were disrupted by three freeze-thaw cycles at $193 \mathrm{~K}$. The soluble and insoluble cell fractions were separated and clarified by centrifugation at $3000 \mathrm{~g}$ for $30 \mathrm{~min}$. An Ni-purification plate was made by adding $150 \mu \mathrm{H}_{2} \mathrm{O}$ and $25 \mu \mathrm{l} \mathrm{Ni-NTA}$ agarose (Qiagen) to each well of a MultiScreen plate (MABVN1250, Millipore). The liquid was drawn through the filter by a vacuum manifold. The NiNTA agarose was equilibrated in $150 \mu$ pellet buffer $(20 \mathrm{mM}$ Tris- $\mathrm{HCl}, 100 \mathrm{~m} M \mathrm{NaCl}$ ) before the transfer of $50 \mu \mathrm{l}$ of clarified lysate and plates were agitated for $30 \mathrm{~min}$ at $277 \mathrm{~K}$ and spun down at $100 \mathrm{~g}$ for $30 \mathrm{~s}$. Unbound protein was washed away with $200 \mu \mathrm{l}$ wash buffer $(20 \mathrm{~m} M$ Tris- $\mathrm{HCl}$ pH 8.0, $300 \mathrm{~m} M \mathrm{NaCl}, 500 \mathrm{~m} M$ imidazole, $5 \%$ glycerol, $5 \mathrm{~m} M$ $\beta$-mercaptoethanol) three times. $50 \mu$ elution buffer $(20 \mathrm{mM}$ Tris- $\mathrm{HCl}, 500 \mathrm{~m} M \mathrm{NaCl}, 40 \mathrm{~m} M$ imidazole, $5 \%$ glycerol, $5 \mathrm{~m} M \beta$-mercaptoethanol) was added and the plates were agitated for $\sim 5 \mathrm{~min}$ at $277 \mathrm{~K}$. Eluate was collected into a new plate by centrifugation at $100 \mathrm{~g}$ for $1 \mathrm{~min}$. Lysates were applied to a Whatman nitrocellulose membrane as $1.5 \mu \mathrm{l}$ spots and were air-dried at room temperature.

\subsection{Detection of proteins}

Blot membranes were soaked with TBST buffer $(20 \mathrm{mM}$ Tris- $\mathrm{HCl} \mathrm{pH} 7.5,150 \mathrm{mM} \mathrm{NaCl}, 0.05 \%$ Tween-20) for $10 \mathrm{~min}$ on a shaker at room temperature (RT). Membranes were washed four times for $15 \mathrm{~min}$ with TBST on the shaker. After washing, incubation with INDIA HisProbe-HRP (Pierce Biotechnology Inc., USA) diluted 1:5000 in $10 \mathrm{ml}$ TBST was performed for $60 \mathrm{~min}$ with gentle shaking. The membrane was washed at least four times before incubation with SuperSignal West Pico Substrate (Pierce) used according to the manufacturer's protocols and the signal was detected using a Fluor-S MultiImager (BioRad) CCD camera and associated Quantity One software v.4.2.1.

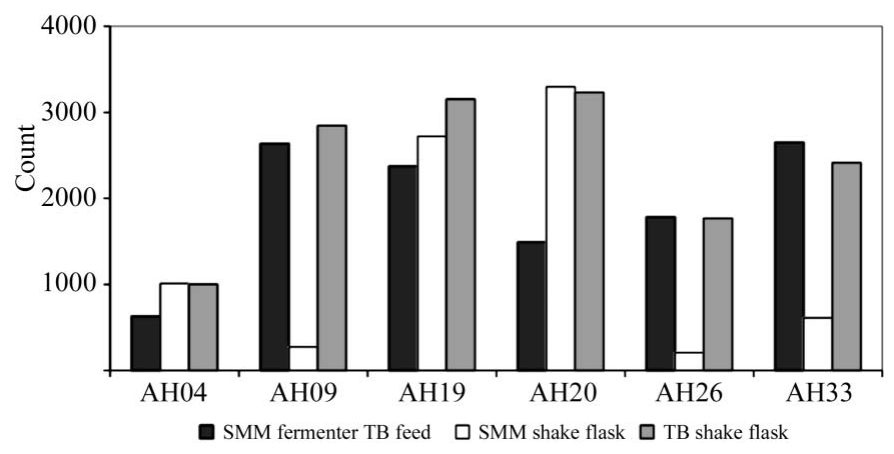

Figure 5

Dot-blots by count from protein expression of each protein from shaker flasks and the fermenter. 


\section{Results and discussion}

To investigate the usefulness of the GRETA multifermenter for structural genomics applications, we performed a large number of fermentation tests using six human proteins. Fermentations under various conditions using the GRETA multifermenter and in baffled-flask processes typically used in structural genomics programmes were performed to allow the comparison of (i) the yield of cells and (ii) the amount of soluble protein produced per unit of cells. Initially, fermentations in the GRETA multifermenter were carried out without fed-batch in order to investigate the basic effects of media. Later, these processes were optimized using fed-batch sequences to obtain higher OD. To test the maximum culture densities sustainable in the GRETA multifermenter, noninduced cultures at $310 \mathrm{~K}$ were grown where OD 120 was reached in $24 \mathrm{~h}$. Six parallel cultures applying the same strain and the same culture conditions provided very similar growth curves, indicating the high reproducibility of the processes carried out in the GRETA multifermenter (data not shown).

For the six human proteins used in the comparative study, the initial fermentation after inoculation was carried out at $310 \mathrm{~K}$. Induction was performed after lowering the temperature to $291 \mathrm{~K}$. Low temperature is often favourable (Neubauer \& Winter, 2001) for producing soluble proteins and is used in many structural genomics projects. OD was also measured offline as an additional control and to determine the final ODs at harvest. Typically, the final ODs for the fed-batch process on GRETA were in the range 50-110 OD (Fig. 4), while the ODs in baffled flasks were in the range 10-25 OD.

Preliminary yield of soluble proteins per unit of cells was measured using small-scale affinity purification followed by dot-blot procedures. ODs were normalized before affinity purification to secure constant cell mass. The expression levels of three proteins (AH19, AH20 and AH26) were very robust under most expression conditions, while three other proteins (AH04, AH09 and AH33) were more sensitive to the fermentation protocols used. The yield of protein per OD unit for the final fed-batch fermentations was quantified in more detail and compared with baffled-flask fermentations (Fig. 5). The results show that the high-density cultures produce similar amounts of soluble protein per cell as baffled-flask cultures. GRETA also produces 2-5 times more cell mass than baffled flasks and the system is well suited for work on medium- and low-expressing proteins. This, together with the lowered media and labour costs of the GRETA fermentations and the high reproducibility of the cultures, makes GRETA an attractive platform for scale-up fermentation in structural genomics programmes.

This work was supported by the European Commission as part of SPINE (Structural Proteomics In Europe) contract No. QLG2-CT-2002-00988 under the Integrated Programme 'Quality of Life and Management of Living Resources', the Swedish Research Council and the Wallenberg Consortium North.

\section{References}

Dieckman, L., Gu, M. Y., Stols, L., Donnelly, M. I. \& Collart, F. R. (2002). Protein Expr. Purif. 25, 1-7.

Edwards, A. M., Arrowsmith, C. H., Christendat, D., Dharamsi, A., Friesen, J. D., Greenblatt, J. F. \& Vedadi, M. (2000). Nature Struct. Biol. 7, 970-972.

Heinemann, U., Frevert, J., Hofmann, K. P., Illing, G., Maurer, C., Oschkinat, H. \& Saenger, W. (2000). Prog. Biophys. Mol. Biol. 73, 347-362.

Lesley, S. A. \& Wilson, I. A. (2005). J. Struct. Funct. Genomics, 6, 71-79.

Neubauer, P. \& Winter, J. (2001). Recombinant Protein Production with Prokaryotic and Eukaryotic Cells. A Comparative View on Host Physiology, edited by O.-W. Merten, D. Mattanovich, C. Lang, G. Larsson, P. Neubauer, D. Porro, P. W. Postma, J. Teixeira de Mattos \& J. Cole, pp. 196-260. Dordrecht: Kluwer Academic Press. Studier, F. W. (2005). Protein Expr. Purif. 41, 207-234. 